\title{
Mission Statement
}

Gerontology was founded by F. Verzár in 1957 and thus is the journal with the longest tradition in the field. While most other journals focus on specific areas of gerontological research, Gerontology has a very broad scope. This is reflected by four Sections to which manuscripts are allocated, namely (1) Clinical and Epidemiological, (2) Experimental, (3) Behavioural, and (4) Regenerative and Technological. This broad scope takes into account many of the facets of current aging research, a field that continues to move into the centre of scientific interest, both from basic and applied viewpoints.

(1) The Clinical and Epidemiological Section accommodates original work in these areas that are of interest to a broader readership. Papers covering research on clinical and epidemiological aspects in all fields of medicine will be considered. Manuscripts of mainly geriatric content will not be published in Gerontology.

(2) The Experimental Section contains experimental gerontological work, ranging from molecular over cellular to organismal aging, including all experimental aging models.

(3) The Behavioural Science Section publishes work on behavioural aspects of aging in experimental animals and humans, again taking into account the necessity to address a broader rather than specialized audience only.

(4) The Regenerative and Technological Section tries to attract interesting, original work from regenerative biology, such as comparative studies on mechanisms regarding regenerative processes in animal species, which are models for the situation in humans.
In addition, this section also harbours papers on technological aspects. This topic has gained increasing importance during the last decade. However, so far there has been no forum for the publication of this kind of work in direct connection with biological and behavioural research thus exposing a broader audience with biogerontological expertise to this discipline. Although the human body appears to be an optimal compromise developed during evolution to its present state, attempts to improve it beyond this state ('enhancement') are being discussed.

\section{Ethical Requirements}

Appropriate proof has to be provided that all ethical prerequisites have been fulfilled. These include permission granted by responsible Ethical Committees and informed consent of participants in studies on human subjects, as well as permission obtained from Review Boards for animal experiments.

\section{Disclosure of Conflicts of Interest}

All forms of funding and support, including that from companies, and any potential competing financial interests should be acknowledged in the Cover Letter to the Editor-in-Chief.

Conflict of Interest statements will be published at the end of the article.

\begin{tabular}{ll}
\hline KARGER & ( ) 2010 S. Karger AG, Basel \\
0304-324X/11/0571-0097\$38.00/0 \\
$\begin{array}{l}\text { Fax +4161306 1234 } \\
\begin{array}{l}\text { E-Mail karger@karger.ch } \\
\text { www.karger.com }\end{array}\end{array}$ & $\begin{array}{l}\text { Accessible online at: } \\
\text { www.karger.com/ger }\end{array}$
\end{tabular}




\section{Types of Manuscripts}

Gerontology publishes the following types of manuscripts:

(1) Original Research Papers (max. 6,000 words and 40 references).

(2) Short Communications. These must contain data derived from front-edge research that deserve especially fast processing and are of potential interest for a large fraction of the readership of Gerontology (max. 2,000 words and 10 references).

(3) Invited Mini-Reviews (max. 4,000 words and 20 references) and occasionally Invited Extensive Reviews. They are to be submitted exclusively upon solicitation by the Editors or Editors of Special Issues. All review articles undergo the same peer-review and editorial process as original research papers.

(4) Letters to the Editor (max. 1,000 words plus and 10 references). Letters may be self-sustaining or represent a concise statement concerning a publication that recently appeared in Gerontology. In exceptional cases, they may also address data published in another journal. All Let- ters have to be submitted within one month after the publication of the paper in question.

(5) The Debate and Viewpoint Sections publish arguments, critical statements and theoretical papers reflecting the authors' views on mechanisms of the aging process in all areas within the scope of Gerontology. Manuscripts are to be submitted exclusively upon solicitation by the Editors and be limited to 4,000 words and 20 references.

(6) Images in Gerontology. Images can be submitted under all headings, i.e. from experimental to technical aspects of gerontology. They should contain exciting and graphically optimally reproducible photographs with a short, self-explanatory legend. Each Image plus legend and references should not exceed one printed page.

(7) Editorials will be written exclusively by the Editors and address timely topics of gerontological research.

Manuscripts far in excess of the limits (text and/or number of references) as specified above will not be processed.

Georg Wick, MD, Editor-in-Chief 